\title{
Quando o indivíduo se transforma: reflexões a partir de Mead, Goffman e Garfinkel
}

Guilherme Figueredo Benzaquen ${ }^{1}$

Resumo: O artigo pretende refletir sobre como a teoria sociológica aborda a questão da crise no e do indivíduo. Para tanto, irei partir de Mead e suas análises pragmatistas sobre o self para depois abordar, de forma comparativa, as transformações do indivíduo em Goffman e Garfinkel. Os três autores serão postos em diálogo e esse esforço analítico possibilitará uma análise de como desenvolveram suas teorias principalmente suas concepções de indivíduo, ação social e ordem social.

Palavras-chave: Geroge Herbert Mead; Erving Goffman; Harold Garfinkel; indivíduo.

Abstract: This paper is a reflection about how social theory addresses the question about crisis in and of an individual. Therefore, I will start with Mead and his pragmatist analysis of the self. After, I will comparatively adress the transformations of the individual in the work of Goffman and Garfinkel. The three authors will be articulated and this theoretical effort will allow us to understand their concepts of individual, social action and social order.

Keywords: Geroge Herbert Mead; Erving Goffman; Harold Garfinkel; individual.

\footnotetext{
${ }^{1}$ Cientista Social, mestre em sociologia pelo IESP/UERJ. Doutorando em Sociologia no Programa de Pós-Graduação de Sociologia da Universidade Federal de Pernambuco. E-mail: benzaquenguilherme@gmail. com
} 


\section{Introdução: o problema em Mead}

Cíclicos ou não, períodos de transformações acentuados são fenômenos históricos recorrentes. Aimportância da compreensão desses momentos foi percebida pelos principais teóricos sociais - quer o chamem de crises, anomias, rupturas ou revoluções. Assim como cada um desses conceitos têm suas particularidades, o enfoque também varia dando, por exemplo, prioridade para explicações causais, tentando descrevê-los ou propondo superações. O começo da sociologia é fruto de um desses momentos e a compreensão das transformações da modernidade foi central em todos autores considerados clássicos. Essa questão se faz tão importante porque através dela se pensa a própria história, em suas rupturas e continuidades. Irei, nesse ensaio de teoria social, modestamente me juntar a esse esforço, fazendo uma análise das contribuições de três autores já canônicos da sociologia.

De forma mais específica, partirei de uma questão levantada por George Herbert Mead que em seus termos formulou: como o self se reconstrói quando há um problema que impede sua continuidade? O que significa que aqui a crise e sua superação serão pensadas no âmbito dos indivíduos. Se esse é um problema muito importante para a psicologia, defendo que a sociologia é uma disciplina que muito tem a dizer sobre o tema, o que ficará claro desde o começo com a análise da concepção de self social de Mead. Depois de formulada a questão que nos concerne e como Mead a soluciona, poderemos partir para a análise de como Erving Goffman e Harold Garfinkel deram continuidade a uma teoria da reconstrução do indivíduo. A estratégia adotada foi a de sistematização de conceitos relevantes para a resposta da pergunta apresentada, tentando perceber as proximidades e as distâncias entre os autores. Essa busca teórica me possibilitará trabalhar como os autores desenvolveram suas teorias, principalmente suas concepções de indivíduo, ação social e ordem social.

Em qualquer contato com a obra de Mead, fica claro quão central era para o autor o problema do self - basta lembrarmos que sua compilação de textos mais conhecida se chama Mind, Self and Society (1972). Ele acreditava que uma resposta correta a essa questão o permitiria fazer uma defesa das ciências sociais como ciência. Mead argumenta que se as ciências sociais fossem exatas como a matemática, o self seria pensado da mesma forma que objetos físicos. Elas ainda não teriam se desenvolvido a ponto de conseguirem realizar essas definições, porém esse foi um dos grandes esforços teóricos do autor (MEAD, 2011), pois, assim como outros autores clássicos da sociologia, havia nele um esforço para demarcar os objetos, objetivos e limites da disciplina. 
O self como objeto das ciências sociais é uma relevante contribuição do autor por conta de sua concepção do self social. Comecemos, portanto, pelo surgimento do self nos indivíduos. Mead argumenta que a formação do self no bebê é tardia e é construída baseada na experiência de outros selves. No começo, as crianças percebem apenas parcialmente seus selves, assim como percebem parcialmente suas mãos e pés. O self só surge quando, em interação com outros selves, a criança se torna um objeto ao poder identificar e analisar seus próprios gestos, atos e condutas (MEAD, 2011, p. 67). Ou seja, um self para existir requer tanto a interação quanto a capacidade de se colocar como objeto. O que significa que esse é um conceito que permite a articulação entre o individual e o social e que está baseado na capacidade humana de comunicação. Nós temos a capacidade de imaginar o papel desempenhado por outros selves e é devido a essa capacidade que conseguimos interagir em sociedade. Portanto, todo self é formado por e forma outros selves.

Aqui se faz necessário incorporar a nossa discussão os conceitos de eu e mim que estão em relação direta com o de self e são fundamentais para a percepção dele tanto como sujeito quanto como objeto. Mead descreve o mim como o self consciente que pressupõe um eu. O self nunca aparece conscientemente nos indivíduos como um eu, ele é um objeto, um mim. Se, por um lado, o eu age em direção a si mesmo e a outros, por outro, o mim é o alvo da ação do eu. O eu é o momento da criatividade - que será, como veremos adiante, central para a concepção pragmatista da ação. Já o mim é a sociedade introjetada no indivíduo e como ele vê a sociedade. O mim é constantemente transformado pelo eu, o que faz com que haja na obra de Mead uma dinâmica de transformação interna. Além disso, essa interação entre esses conceitos revela que o self age com referência a outros, mas é também imediatamente consciente da sua ação, ou seja, é reflexivo.

Voltando para o conceito de self e seguindo Wiley (1994), é possível afirmar que essa noção tem em Mead cinco características marcantes. (1) É formado em diálogo e está sempre em relação com outros selves, ou seja, é dialógico tanto internamente quanto interpessoalmente; (2) o que consequentemente o torna social, público e político. (3) É pensado de forma igualitária, pois os equipamentos psicológicos dos seres humanos são tidos como iguais. Formulação importante na luta pela democracia e de combate a teorias racistas que vigoravam na época. (4) É voluntarista porque os indivíduos têm a capacidade de auto-determinação, de poderem escolher. (5) E, por fim, o self é cultural, pois está relacionado às capacidades simbólicas humanas.

É importante frisar que Mead se contrapõe a uma ideia de um indivíduo autocentrado. O indivíduo só é constituído a partir do outro, pois as relações sociais 
influenciam o self. Essa influência leva em consideração que o self é um interpretador ativo das relações com os outros e, dessa maneira, ele entra na vida social interpretando e reformulando em sua mente as atitudes do outro generalizado. A esse respeito vale relembrar o já clássico recurso argumentativo de Mead da brincadeira e do jogo para explicar o outro generalizado. Enquanto que a brincadeira é pensada como interação ainda muito espontânea, o jogo requer regras e organizações. No jogo age a consciência para saber o seu papel e o indivíduo só compreende seu papel a partir da percepção do papel dos outros, de forma simultânea e a partir de regras. O outro generalizado surge dessa interação de gestos e é, em grande medida, fruto da linguagem. Ele tem como uma de suas premissas a abstração das particularidades (SILVA, 2007). É possível afirmar que o outro generalizado são as regras gerais da vida social, o que significa que o mundo social é visto como algo construído na interação dos símbolos.

Agora que está exposta a concepção de self e de outro generalizado, é necessário fazer uma breve explicação sobre a teoria da ação de Mead para podermos lidar com o problema da reconstrução do self. Segundo Joas (1993), a teoria pragmatista da ação fez com que fosse possível olhar para formas de ação que estavam sendo ignoradas e olhar para as já estudadas de uma nova forma. Há no pragmatismo de Mead um questionamento acerca da ideia de que a interrelação entre indivíduos seja somente a interconexão de suas ações utilitariamente orientadas ou baseada em um consenso normativo. O pragmatismo não aceitou o modelo da ação racional como tipo ideal histórico nem como pressuposto psicológico. Há toda uma tradição de interpretação da ação que não cai nesse dualismo, mas que se centra no caráter criativo da ação humana: o pragmatismo norte-americano se encaixa aqui. A sua metáfora guia é a solução criativa de problemas por uma inteligência que experimenta. Como explica Silva (2007), para o pragmatismo, quando há algum empecilho ou tendências conflitivas em um ato, surge um problema. A sua resolução requer a reconstrução criativa da situação: muitas possibilidades de resposta são consideradas pelo indivíduo que decide por aquela que lhe parece mais adequada para a resolução do problema. Portanto, na teoria da ação desenvolvida por Mead, a criatividade é central.

Essa forma de pensar a ação como resolução de problemas é a ponte para pensarmos a reconstrução do self. Quando é mera organização de hábitos o self não é auto-consciente, porém, ao surgir um problema que obstaculiza sua continuidade, há uma crise em sua organização, pois aspectos particulares do self são questionados e aparecem diferentes tendências de reconstituição da normalidade. Depois desse processo de reestabelecimento moral surge um self transformado que está relacionado com a sua capacidade de auto-objetificação. Ele se coloca como objeto, na interação entre o mim e 
o eu, para poder lidar com os obstáculos que encontrou. Nesse intermédio há uma disputa de valores defendidos pelo self em crise e em transformação. Porém a resolução não vem da tensão dos aspectos do self ligados a papéis específicos, mas da reconstrução que desenvolva uma personalidade que melhor corresponda às novas situações. O indivíduo se engaja em um processo de construção de um novo mundo harmonizador dos conflitos e de um self que se encaixe nesse mundo (MEAD, 2011). É importante destacar que essa reconstrução do self é vista como um processo de transformação em que quando o novo estado é atingido, ele durará até o surgimento de um novo obstáculo intransponível na normalidade daquele self.

Essa formulação teórica é distinta da dos outros autores, que a pensam de forma mais contingencial e flexível. Porém, ela fornece alguns parâmetros para continuarmos a análise e focaremos agora nas formulações de Goffman.

\section{Goffman: as rupturas na dramaturgia}

Goffman teve uma influência grande de Mead, porém retrabalhou suas questões de maneira própria. Sua obra é comumente associada às ideias de interacionismo simbólico, o que, de forma bastante resumida, se dá devido à ênfase das suas análises nas interações simbólicas entre os indivíduos, e de dramaturgia, devido ao seu esforço de pensar a vida social através de uma analogia com o teatro. Ele se colocou como questão o que torna as interações possíveis e encontrou um modelo para respondê-la a partir das representações cênicas. Esse modelo tem limitações - algumas reconhecidas pelo próprio autor - porém se mostra bastante elucidativo de uma série de interações face a face, que são definidas por três características: se passam em um breve período de tempo, têm uma extensão limitada no espaço e são eventos restritos àqueles que interagem. Dessa maneira, Goffman faz uma sociologia das ocasiões, pois está interessado em analisar uma estrutura estabilizada normativamente que é mutante, dependendo das chegadas e partidas dos que interagem. Portanto, o elemento da copresença é fundamental para suas análises, pois mais do que entender o indivíduo em sua particularidade, o objetivo é perceber as relações que surgem dos atos de pessoas presentes umas com as outras (GOFFMAN, 2011). Ou seja, Goffman se importa com como os atores agem (conscientemente ou não) em interação e como as pessoas percebem essa ação.

Em uma primeira aproximação, trabalhar o conceito de self em Goffman apresenta algumas dificuldades. A primeira é o fato da sua concepção de indivíduo ter uma possível recepção polêmica, pois muitas vezes Goffman ressalta o lado sombrio dos seres humanos, 
como a manipulação e o cinismo. Porém, essa dificuldade é superada quando percebemos que a sua teoria é muito mais complexa e engloba ações de caráter mais ritualístico. Uma dificuldade que persiste mesmo depois de uma leitura atenta é a de que em Goffman o uso de conceitos como self, indivíduo e pessoa muda no desenvolvimento de sua obra - algo bem analisado por Smith (2006).

Em suas discussões sobre os indivíduos, Goffman defende que a sociologia também lide com questões relativas à personalidade. Ele tenta constantemente estabelecer as bases sociais dos indivíduos, que surgem principalmente da ideia de ordem interacional. A definição de Goffman de ordem pode ser resumida na seguinte frase: “o mundo, na verdade, é uma reunião" (GOFFMAN, 1975, p. 41). A ordem interacional garante sua continuidade através das restrições impostas pelas necessidades dos selves em copresença. Essa é uma inversão das definições mais comuns da ordem restringindo as manifestações dos selves. Ele argumenta, baseado em sua noção de apresentação do self, que as necessidades da interação e do self social são fontes de restrições para o social. Se a noção de self social já estava em Mead, o seu avanço é perceber como isso gera restrições para a ordem interacional (RAWLS, 1987). Goffman, inclusive, menciona várias vezes Mead, porém o critica por sua suposta fixidez do self, e ao definir esse conceito o atrela à necessidade das interações, uma conceituação que se assemelha ao de seu antecessor pragmatista. Com isso questiona as concepções de um self soberano perante a sociedade e também as concepções da unicidade dos indivíduos. Mais do que uma definição ontológica dos seres humanos, Goffman está interessado nas evidências empíricas que tornam os selves visíveis. Ele acaba concebendo os indivíduos de forma extrínseca, ou seja, pensa as características que geralmente são definidas como pessoais (as emoções, por exemplo) como influenciadas pelas interações exteriores. Aqui fica clara a centralidade das interações para Goffman: mais do que pensar os indivíduos psicologicamente, interessa-o entender as suas interações, ao ponto de importar prioritariamente as características que possibilitam as relações. É perceptível que há uma clara influência de Mead porque ambos estão refletindo sobre a experiência dos indivíduos quando agem socialmente. Para ambos, não interessa separar os indivíduos e suas condutas, esses conceitos são mutuamente formativos.

Sobre como esses atores agem socialmente, há uma ênfase constante na obra de Goffman da capacidade dos atores de controlarem as atividades interacionais e gerenciarem as impressões que passam. Isso pode fornecer uma impressão do indivíduo em sua obra como sendo excessivamente maquiavélico, porém há uma outra parte de 
suas formulações que deve ser levada em consideração: as interações ritualísticas, nas quais os indivíduos afirmam um respeito pelos outros e pelo que eles acham ser a forma correta de se relacionar. Os atores estão enquadrados em uma escala que tem como casos limites o egoísmo daquele que calcula e manipula estrategicamente suas impressões e o altruísmo daqueles que dão e recebem deferências. Enquanto que um está próximo de um self manipulador, o outro está mais de um performático (SMITH, 2006). No geral, portanto, é possível perceber que a noção de self em Goffman tem um caráter muito mais fragmentário do que a apresentada por Mead. Esse traço será importante para perceber as respostas do autor sobre a questão da transformação do self.

Quando estão desempenhando um papel, os indivíduos requerem dos observadores que levem a sério suas atuações. A fachada é central nesse processo de representação, ela é "a parte do desempenho do indivíduo que funciona regularmente de forma geral e fixa com o fim de definir a situação para os que observam a representação" (GOFFMAN, 1975, p. 29). Os que representam podem ter duas formas de pensar suas atuações: estarem compenetrados acreditando que a atuação corresponde aos seus eus verdadeiros, os sinceros, ou não estarem compenetrados, não crendo em suas atuações, sendo os cínicos, a quem enganar sua plateia por um bem próprio ou um bem coletivo se justifica. A aproximação de um desses tipos faz com que os atores encontrem garantias para a manutenção de seus papéis, por isso que, mais do que um fingimento, as máscaras colocadas pelos indivíduos são parte do verdadeiro eu deles porque são aquilo que eles gostariam de ser. Nesse sentido, em Goffman, a performatividade é parte central da compreensão do self.

Há uma expectativa de coerência no desempenho da atuação dos atores. Essa coerência deve se dar tanto como continuidade com o papel desempenhado anteriormente quanto com o papel que deve ser desempenhado em determinada situação. Goffman defende que um papel novo é construído a partir do acumulado em outras representações. Uma nova fachada raramente é mesmo uma nova fachada, ela é a escolha entre fachadas possíveis. A mudança de papéis é vista por Goffman como algo corriqueiro, pois todos os indivíduos têm múltiplos papéis de acordo com a audiência. Porém, nas variações entre as plateias, há uma tendência dos atores defenderem que a representação que desempenham no momento é a única ou a mais essencial.

Há casos em que essas mudanças de papéis extrapolam as situações corriqueiras. A ruptura da representação pode ter consequência em três níveis de abstração: personalidade, interação e estrutura social. Do ponto de vista da interação, a situação pode deixar de ser definida adequadamente e os participantes ficarem sem saber como agir. Com relação à 
estrutura, ela pode sofrer consequências porque todo ator é identificado com um grupo de colegas, com equipes, e a legitimidade dessas coletividades está em jogo em todas as interações. Quando há uma ruptura, toda essa estrutura pode ficar comprometida. Sobre a personalidade, é possível afirmar que os atores atribuem uma parte significativa de suas concepções de si mesmo à capacidade de manterem determinadas interações. A ruptura pode causar um descrédito sobre a sua capacidade de sustentar determinado papel (GOFFMAN, 1975).

Goffman percebe uma série de formas propositais ou não da ruptura dos papéis. Um dos casos mais paradigmáticos de reconstrução do self se dá em instituições totais. Em manicômios, prisões e conventos, Goffman (1974) pensa os constrangimentos organizacionais do self e as resistências daqueles que não cedem às transformações. Esse é um caso extraordinário de reconstrução do self porque se passa em instituições totais que têm como objetivo justamente transformar a individualidade dos pacientes através de um isolamento do resto do mundo. As características pessoais dos indivíduos antes da entrada nas instituições são descartadas para que eles se submetam à padronização desejada pelas autoridades. Percebendo as mudanças provenientes de medidas institucionais, Goffman chega à conclusão de que os selves são muito vulneráveis e podem ser destruídos e reconstruídos, apesar das resistências pessoais. Levando em consideração que nesse caso os indivíduos estão em uma situação extrema, ainda assim é possível perceber que as formulações de Mead sobre a transformação do self se encaixam parcialmente. Assim como Mead, há uma defesa de que o novo self surge para ser possível uma adaptação com o ambiente, porém, ao contrário dele, a transformação não passa por um esforço individual de solução do problema, mas por constrangimentos externos.

Outra forma de ruptura nos papéis desempenhados surge quando há uma situação de constrangimento (GOFFMAN, 2011). Os atores tentam a todo o momento fazer uma manutenção do controle expressivo, porém, nas interações face a face, há sempre a possibilidade de que a interação saia do seu curso natural, que haja uma ruptura. Esse desvio do estado normal pode ser reconhecido através de pequenos gestos corporais e é uma dificuldade para a continuidade das interações. O constrangimento tem como causa principal uma expectativa com relação à interação não realizadas. Essa dificuldade pode ser rapidamente superada ou pode gerar uma fissura maior, ou seja, pode haver um incidente constrangedor em um evento ou o evento todo pode ser constrangedor. Muitas vezes manter a aparência do não constrangimento é parte fundamental da interação: o constrangido finge não o estar e os outros fingem não percebê-lo. Porém, há momentos de crises acentuadas 
que fazem com que haja uma ruptura nos grupos sociais e uma reconstrução dos papéis de cada um dos atores. Essas situações críticas são um agravamento da tendência dos atores a um afastamento de situações constrangedoras. Goffman não elabora como se dá essa reconstrução pós-constrangimento, mas de acordo com o discutido anteriormente, podemos inferir que seja a partir de uma seleção entre diferentes fachadas possíveis. Outra possibilidade de ocorrência do constrangimento que é de interesse para nossas indagações ocorre quando uma pessoa tem dois papéis conflitantes que não podem ser conciliados em uma determinada interação. "Ao demonstrar constrangimento quando ele não pode ser nenhuma das duas pessoas, o indivíduo abre a possibilidade de no futuro poder efetivamente ser uma delas" (GOFFMAN, 2011, p. 108). O constrangimento pode, dessa maneira, ser funcional para o reestabelecimento de uma participação natural na sociedade, para uma reconstrução do self.

Depois dessa sistematização fica evidente que essas formulações de Goffman têm um foco distinto e são um desdobramento muito produtivo das formulações de Mead. Enquanto Mead, um psicólogo social, estava interessado em explicar a origem social do self (a emergência do self), Goffman estava mais preocupado em entender como o self se sustenta ou se mantém nas interações e ao longo da vida. No próximo tópico veremos a teoria de Garfinkel e realizaremos aproximações e distanciamentos com a teoria de Goffman.

\section{O passar-se em Garfinkel}

Ao contrário de Mead e Goffman, Garfinkel, o criador da etnometodologia, nos fornece um caso empírico bastante detalhado do passar-se em uma pessoa: o caso Agnes. Nesse texto, Garfinkel (2014) pretende, através de um caso de construção de identidade de gênero, defender a sua teoria de que as pessoas são metodólogas práticas, ou seja, têm a capacidade reflexiva de construir e manipular a normalidade como uma realização contínua e prática. Esse caso serve de parâmetro para uma análise do gerenciamento das "sexualidades normais" porque Agnes apresentou em suas entrevistas consciência da organização e da operação das estruturas sociais necessárias para aqueles que têm seus status sexuais garantidos. Segundo Armitage (2001), no já clássico quinto capítulo dos Estudos em Etnometodologia, o autor teve um duplo objetivo: entender como Agnes conseguiu se passar por uma "mulher normal" e entender os métodos utilizados pelas pessoas no gerenciamento das atividades interpessoais de suas vidas. Realizou também 
um duplo feito: forneceu uma demonstração metodológica da natureza contínua da produção social do gênero e um exemplo da hipótese etnometodológica de como as pessoas produzem atividades práticas estáveis e relatáveis no cotidiano.

Para compreender o passar-se temos que primeiro saber quem é Agnes. Ela é descrita como uma garota de dezenove anos criada como garoto que tem todas características de uma "mulher normal", mas que tem um pênis e um testículo completamente desenvolvidos. Garfinkel faz uma descrição da sua aparência que reforça o seu lugar como "mulher". Ela nasceu e foi criada como um menino, porém a atribuição de um papel masculino foi desempenhada com dificuldade, o que gerou uma relação de conflito com a escola (da qual saiu aos dezessete anos). Já adulta, mudou-se para Los Angeles, onde arrumou um namorado e trabalhou em uma companhia de seguro. Em cinquenta e nove, conseguiu fazer a operação que removeu seu pênis e escroto e construiu sua vagina. Garfinkel a conhece nesse processo da operação e seu estudo é baseado em uma série de entrevistas realizadas na época. Agnes é um exemplo do que Garfinkel fala sobre a capacidade de explicação dos indivíduos, pois descreve, critica e idealiza as suas situações, ou seja, dá sentido ao mundo. Nesse processo Agnes fez um relato biográfico de uma existência completamente feminina e os traços relacionados a uma educação masculina foram relatados como dolorosos. Em seu relato, o pênis era sempre uma parte do corpo renegada, enquanto que os seios eram uma parte da qual tinha orgulho.

A partir desse caso ficou claro para Garfinkel que os status sexuais são panos de fundo essenciais das práticas cotidianas e que há um controle constante em todas as sociedades da mudança de status das pessoas, principalmente no caso de status sexuais. Agnes tinha uma preocupação prática com a sexualidade feminina competente e concordava com o fato moral de que as pessoas são seres sexuados. Queria, acima de tudo, ser tratada como uma mulher natural, normal. Para entender o que isso significa, Garfinkel elenca uma lista de propriedades das pessoas naturais que está baseada na premissa básica de que quem é normal está em uma das duas categorias dicotômicas: homem ou mulher. São propriedades que estão baseadas no senso comum, mas que também são expressas por autoridades científicas. No limite, o normal baseia-se no que está de acordo com os costumes. Há uma "comunidade de entendimento" sobre a sexualidade natural que defende que a filiação a uma categoria do sexo natural vale para toda a vida do indivíduo, por isso que Agnes teve que lidar com uma série de questões para se legitimar no seu processo de passar-se. Uma de suas primeiras atitudes relativas a isso foi aderir ao discurso do senso comum e defender que ela sempre fora uma mulher e que o erro estava nas pessoas que não haviam compreendido os "fatos reais". 
A operação foi o momento mais paradigmático de um processo duradouro na vida de Agnes. Ela estava envolvida no que Garfinkel chamou de passar-se, ou seja, “o trabalho de adquirir e assegurar os direitos de viver como mulher natural, normal, tendo continuamente que prever a possibilidade de detecção e consequente ruína, implícita nas condições socialmente estruturadas" (GARFINKEL, 2014, p. 106). O passar-se tem um duplo sentido para descrever esse processo. Em primeiro lugar, se refere à transformação de um status sexual masculino, na infância, para um status sexual feminino. Em segundo lugar, há um sentido mais sutil que remete à ideia de se passar: Agnes tinha que cotidianamente se passar por uma mulher natural para garantir seu status. Aqui já podemos perceber uma distinção muito clara com a maneira como Mead resolveu a questão da reconstrução do self, pois ao contrário de Mead que pensava esse processo como irreversível e estabelecedor de uma nova ordem, em Garfinkel, de forma parecida com Goffman, o passar-se requer um esforço constante para manter essa ordem e esse novo status. Isso está de acordo com a teoria de gênero de Garfinkel como realização situada (ARMITAGE, 2001): ser membro de uma categoria sexual se sustenta por uma série de práticas circunstanciais e contingenciais, apesar do autor também preservar o sentido de que essa filiação está relacionada com um fato moral, natural e normal da vida.

Os esforços para adquirir o status de uma mulher natural foram muitos. Uma das maiores dificuldades, e que gerava as outras, era a de conseguir se legitimar socialmente como uma mulher natural. A mudança para mulher aumentou, aos olhos de Agnes, seu próprio status. Para assegurar essa mudança, ela teria que garantir seu papel como mulher legítima, porque a sua feminilidade só poderia ser reivindicada a custo de vigilância e trabalho. Agnes fez um gerenciamento ativo e deliberado de sua aparência como um objeto perante outras pessoas para legitimar sua passagem, e nesse cuidado teve que lidar com muitas contingências conhecidas e desconhecidas. Os riscos eram muito grandes se ela fosse descoberta. Ou seja, o passar-se não era uma escolha para Agnes, ela tinha que fazê-lo. Parte do esforço de Agnes de se colocar como uma mulher natural envolveu um distanciamento dos homossexuais. Em seu gestual e nas suas repostas, Garfinkel encontrou a defesa de que não era possível uma comparação entre o caso de Agnes e dos homossexuais. Essa preocupação com o gestual é algo recorrente na obra de Garfinkel e está relacionada com sua concepção de que há uma linguagem natural (não linguística) que mantém a naturalidade das situações. Em toda essa explicação encontramos em Agnes um exemplo possível das características dramatúrgicas das interações descritas por Goffman. Ela pode ser lida como uma atriz que desempenha um papel perante uma plateia e que 
tenta evitar os constrangimentos e as rupturas. Porém, antes de considerarmos as duas teorias como espelhadas, adiantamos que há diferenças que serão discutidas adiante.

Garfinkel elaborou um modelo do jogo para pensar esses esforços no passar-se por esclarecer "várias das ocasiões de passagens de Agnes como uma trama de possibilidades ambientais relevantes e sua estrutura operacional" (GARFINKEL, 2014, p. 109). Durante seu cotidiano, muitas foram as ocasiões do passar-se nas quais ela teve que gerenciar seu status de forma similar ao de um jogo. As principais características do jogo que ela teve que recorrer foram o pré-planejamento e uma confiança instrumental nas regras que ela poderia assumir serem conhecidas pelas várias partes da interação de uma forma mais ou menos similar. Nessas ocasiões, Agnes é apresentada como um indivíduo com uma capacidade muito grande de planejamento, tendo escapado apenas algumas coisas de as suas previsões. Porém há também ocasiões do passar-se que o modelo de jogo não analisa apropriadamente. Nas ocasiões em que Agnes aprendia a ser garota o modelo do jogo não convém porque ela aprendia ao mesmo tempo em que interagia. Os padrões tinham que ser aprendidos em situações que não se podia revelar o aprendizado, ao contrário do que ocorre em um jogo. Em ocasiões estressantes de possível quebra do status, o modelo do jogo também não convém pela falta de confiança no respeito às regras.

Sobre o gerenciamento da reivindicação de ser mulher, Garfinkel faz uma análise comparativa da sua teoria com a de Goffman. Antes é preciso ressaltar que com Agnes estamos lidando com um caso singular, pois há uma diferença significativa entre ela e "pessoas normais": a alegação de que era mulher, gerava em Agnes um pensamento de como as pessoas receberiam a informação, ao contrário do que ocorre com as pessoas normais. Segundo o próprio Garfinkel, esse gerenciamento tem similitudes com o processo de gerenciar impressões em ordens sociais, estabelecido por Goffman. Porém Agnes não era uma jogadora, não manipulava as impressões de acordo com um papel definido intelectualmente, ela acreditava fielmente no seu status de mulher. Não é, portanto, a partir da ideia de estratégia que podemos entender seu gerenciamento. A grande distinção com a teoria de Goffman, entretanto, é o fato de, no caso de Agnes, ser um fluxo de ação contínuo, não episódico. O que significa que é necessário levar em consideração o tempo (interno e externo) nesse gerenciamento dela. Garfinkel concorda com uma leitura goffmaniana sobre a importância da dissimulação no caso de Agnes para manter as interações sociais e sobre como ela apresenta um grau de gerenciamento de impressões elevado. Porém discorda do grau de generalidade de Goffman ao atribuir isso a todos os membros da sociedade. Outra discordância mais fundamental, é o fato de que para Agnes 
esse controle era problemático, ela não desejava estar atenta ao seu gerenciamento em todos os momentos da sua vida, mas necessitava assim fazer, ao contrário dos manipuladores de Goffman. Extrapolando as comparações feitas pelo próprio Garfinkel, podemos afirmar que sua leitura de Goffman está muito centrada nos atores cínicos quando há na obra dele uma parte significativa destinada a entender os atores sinceros. O caráter episódico das interações faz com que as atuações variem, por isso não concordamos com Garfinkel quando ele atribui a generalidade da manipulação entre os indivíduos, ela é geral em todos os indivíduos, porém não é geral na vida de um indivíduo.

Agnes era um indivíduo em constante esforço de adaptação, ela tinha uma noção maior do que os outros indivíduos das estruturas necessárias para manter a normalidade das situações e esse conhecimento empresta às ações de Agnes um sabor manipulativo. Ela desenvolveu uma série de modos de reter informações nos seus relatos: eufemismo, usar generalidades, alusões, falar no modo impessoal, exigir descrições acuradas do que havia dito antes de dar uma resposta, tentar extrair a resposta da própria pergunta. Quando podia, Agnes tentava prever as possibilidades de cursos possíveis do acontecimento e tentava direcionar para a que mais lhe favorecesse. Aqui percebemos a concepção de Garfinkel da ação como prática de atores cognoscentes. É importante para ele saber o conhecimento utilizado em uma dada ação, mais do que a motivação da ação (JOAS; KNOBLE, 2009).

Esse estudo sobre Agnes é baseado em seus relatos e ao analisar como Agnes constrói seus relatos, Garfinkel chega a uma série de conclusões. Essa questão é importante porque para a etnometodologia a capacidade de relatar dos indivíduos é uma característica que permite aos atores sociais se comunicarem e tornarem as práticas sociais compartilháveis, é portanto o fundamento da intersubjetividade. Algumas características identificadas foram: Agnes a todo mundo momento lidava com projeções (cujo marco principal era a operação) e com a comparação com os eventos reais que se sucederam. Ela não se dava a "jogos de palavras" de pensar como o mundo poderia ser de outra maneira, pois mais do que mudar o mundo, o interesse dela era se adaptar ao mundo que existia. Nesse sentido, a normatividade de Agnes estava próxima às formulações de Mead sobre a reconstrução do self como busca do self que melhor se adapte ao contexto. Ela tinha também uma capacidade de apreensão dos eventos (seus ritmos e progressões) que conferia a sua narrativa um caráter bastante realista. E, por fim, sua forma de definir o certo e o errado estava baseada na autoridade daqueles que concordavam com ela.

A grande conclusão de Garfinkel com esse estudo é que Agnes revela muito sobre o funcionamento das situações consideradas normais, ou seja, as que não são 
problematizadas. Isso porque ela agia como uma metodóloga prática: "falar seriamente de Agnes como uma metodóloga prática é tratar como realidades seus estudos contínuos das atividades cotidianas como metodologia dos membros para produzir decisões corretas quanto à sexualidade normal em atividades cotidianas" (GARFINKEL, 2014, p. 129). Em sua necessidade de parecer normal, Agnes aprendeu e poderia ensinar às pessoas normais como elas deveriam fazer as suas performances de gênero acontecerem para parecerem normais. Aprendemos com Agnes que as práticas dos membros produzem a sexualidade normal exclusivamente em ocasiões reais. Ela agia de acordo com a ideia de que a sexualidade é fruto de um trabalho inexorável, organizacionalmente localizado que fornece o modo como esses objetos surgem. O que está em consonância com a concepção de ordem, de Garfinkel, como contingencialmente constituída e sustentada pela interação dos indivíduos.

A revelação, alguns anos depois da cirurgia, de que Agnes era um homem que tomava estrogênios roubados da mãe desde os doze anos deixou Garfinkel com um grande problema: ele tinha construído sua perspectiva sociológica num erro entre o que era realidade e mentira. Entretanto, a revelação é vista por Garfinkel, em um breve apêndice escrito após a revelação, como uma confirmação de duas hipóteses etnometodológicas centrais (1) A capacidade de relatabilidade racional das ações práticas de um indivíduo. (2) As situações de interações dos indivíduos exigem uma organização reconhecida e familiar de atividades, porém mascara esses processos de organização e acabam parecendo independentes dos indivíduos. Armitage (2001) defende que Garfinkel foi sábio ao não alterar seu texto porque independente da informação sobre a mentira de Agnes, o esquema textual que ele construiu defende seus argumentos principais. Mas se a revelação reforça algumas premissas básicas da etnometodologia, acaba sobrando uma importante lacuna para a nossa análise que é fato dele ter errado em sua comparação com a teoria de Goffman. O caso de Agnes se aproxima mais ainda da teoria de Goffman quando percebemos o quanto ela pode ser enquadrada na ideia de uma atuação cínica. Ela não necessitava do passar-se por uma crença sincera em seu status de mulher natural, mas precisava assim fazer porque tinha noção da atuação que desempenhava para manter seu papel. 


\section{Considerações finais}

$\mathrm{Na}$ concepção mais comum de mudança, há implícita a ideia de um antes e um depois. Em Mead isso está bem claro, pois o self, quando se defronta com uma situação problemática que o impede de seguir o seu curso natural, vive um complicado processo de deixar criativamente de ser aquele que era e se transformar em um novo que surge após a resolução do processo. Em Goffman, as mudanças de papéis têm um caráter mais reversível de acordo com a situação em que os atores estão atuando. Porém, o autor também leva em consideração as situações mais críticas em que um self tem que abandonar a sua atuação e se transformar. Nesses casos a sua teoria se aproxima das formulações de Mead, pois o indivíduo e as situações têm que ser redefinidas até encontrarem definições que os tornem possíveis novamente - sendo esse processo mais flexível em Goffman. Já em Garfinkel, o antes e o depois se mesclam em um tempo presente em que o indivíduo tem que estar sempre atento. Para ele, o processo tem um caráter mais contínuo de passagem e, mais importante do que definir um antes e depois, é necessário realizar uma distinção mais precisa entre o interno e o externo. O esforço de se passar como mulher natural para Agnes está em constante luta com os riscos externos de descobrimento desse esforço.

Sobre como acontece o processo de transformação, os três autores fornecem explicações bastante interessantes. Mead identifica que após a crise, surgem diferentes tendências que se confrontarão com as necessidades da nova situação social na qual o indivíduo se encontra. A reconstrução virá da adequação do self com a situação em que se encontra. Já Goffman argumenta que após a ruptura, há uma reconstrução a partir de estoques de representação já conhecidos pelos atores. Mais do que uma criação de um self realmente novo, o ator vai escolher aquele que melhor se adéqua ao papel que deve representar. Por fim, Garfinkel argumenta que esse é um processo de esforço constante para evitar os riscos que surgem de um gerenciamento de impressões mal realizado. Esse esforço envolve uma observação de como aqueles que têm o status reivindicado agem para incorporar essas maneiras de agir.

Por fim, gostaria de destacar que em Mead o mais importante não é entender a causa da ruptura, mas como os indivíduos agem para reestabelecer a possibilidade da dimensão coletiva. Goffman dá um peso maior para as causas da ruptura chegando a identificar algumas que são intencionais e outras não, explicando menos detalhadamente o processo de mudança em si. Já Garfinkel está entre os dois autores mesclando as causas do passar-se com o processo contingencial de manutenção dessa transformação. 
GUILHERME FIGUEREDO BENZAQUEN 6 QUANDO O INDIVÍDUO SE TRANSFORMA (...)

\section{Referências}

ARMITAGE, Leia Kaitlyn (2001). Truth, Falsity, and Schemas of Presentation: A Textual Analysis of Harold Garfinkel's Story of Agnes. Electronic Journal of Human Sexuality, Volume 4, April 29.

GARFINKEL, Harold (2014). Passagem e gerenciamento do status sexual em uma pessoa "intersexuada". Teoria e cultura, Volume 9, jan/jul, p. 94-135.

GOFFMAN, Erving (1975). A Representação do Eu na Vida Cotidiana. Petrópolis: Vozes. . (2011). Ritual de Interação: ensaios sobre o comportamento face a face. Petrópolis: Vozes. . (1974). Manicômios, Prisões e Conventos. São Paulo: Perspectiva.

JOAS (1993). Pragmatism and Social Theory. Chicago e Londres: The University of Chicago Press.

JOAS, H.; KNOBLE, W. (2009). Social Theory: Twenty Introductory Lectures. Cambridge: Polity Press.

MEAD, George Herbert (2011). G.H. Mead: a reader. Felipe Carreira da Silva (ed.). Londres e Nova York: Routledge. . (1972). Mind, Self and Society. Chicago: University of Chicago Press.

RAWLS, Anne (1987). The Interaction Order Sui Generis: Goffman's contribution to social theory. Sociological Theory, vol 5, p. 136-149.

SILVA, Filipe Carreira (2007) G. H. Mead: a system in a state of flux. History of the Human Sciences, vol. 20 n. 1, Londres e Nova Déli, p. 45-65.

SMITH, Greg (2006) Erving Goffman. Abingdon e Nova York: Routledge.

WILEY, Norbert (1994) The Semiotic Self. Cambridge e Oxford: The Polity Press.

Recebido em 30/08/2018

Aprovado em 03/12/2018 